\title{
Development and validation of a new questionnaire appropriate to assess respiratory symptoms in current and former smokers without chronic obstructive pulmonary disease: The Respiratory Symptom Questionnaire (RSQ)
}

Stacey McCaffrey ( $\nabla$ stacey.mccaffrey@juul.com ) Juul Labs, Inc.

\section{Saul Shiffman}

Pinney Associates, Inc.

Michael J. Hannon

Pinney Associates, Inc.

Nicholas I. Goldenson

Juul Labs, Inc.

Ryan A. Black

Juul Labs, Inc.

\section{Research Article}

Keywords: validation, measure development, respiratory symptoms, cough, respiratory symptom questionnaire, COPD, e-cigarettes, electronic nicotine delivery system

Posted Date: January 28th, 2022

DOI: https://doi.org/10.21203/rs.3.rs-1297115/v1

License: (c) (i) This work is licensed under a Creative Commons Attribution 4.0 International License. Read Full License 


\section{Abstract}

Background: Smokers who switch completely to electronic nicotine delivery systems (ENDS) may experience reductions in respiratory symptoms (e.g., cough, wheezing). Assessing such symptoms among smokers without respiratory disease using existing respiratory symptom questionnaires is challenging, as these questionnaires are intended for patient populations, such as those with chronic obstructive pulmonary disease (COPD). The current study aimed to develop a respiratory symptom questionnaire appropriate for current and former smokers including those without COPD.

Methods: This research included 3 phases. First, a draft respiratory symptom questionnaire (RSQ) was generated with input from subject matter experts. Second, the RSQ was refined through waves of cognitive debriefing interviews ( $n=49)$ with adult current smokers (Smokers) and former smokers who switched completely to ENDS for $6+$ months (Switchers). Finally, Smokers $(n=202)$, Switchers $(n=208)$, and Former Smokers (no tobacco use in $6+$ months; smoked $10+$ years; $n=200$ ) completed the RSQ for purposes of the quantitative psychometric evaluation.

Results: The first two phases produced a 5-item RSQ that captured relevant symptoms and was interpreted as intended. During Phase 3 the RSQ was evaluated within the context of the graded response model (GRM). GRM assumptions of ordinality of response categories and unidimensionality were met. Test-retest reliability over a 1-week interval was good, and results provided support for convergent validity. Significant differences between Smokers' and Former Smokers' RSQ scores provide initial support for the RSQ's ability to detect change in respiratory symptoms over time. In exploratory analyses, Switchers' RSQ scores were significantly lower than Smokers' scores, but not significantly different from Former Smokers'.

Conclusion: Findings from this rigorous instrument development and validation study provide strong support for the reliability and validity of the RSQ as a measure of respiratory symptoms in adult current and former smokers, including those who may be at risk for developing COPD. The finding that RSQ scores among former smokers who had switched completely to ENDS were significantly lower than current smokers' scores and similar to the scores of former smokers who had quit suggests that switching from cigarettes to ENDS may improve respiratory health.

\section{Background}

Cigarette smoke contains thousands of chemicals that are inhaled and deposited throughout the lungs, causing inflammation of the airways, impairing ciliary clearance and leading to oxidative injury [1-3]. Cigarette smoking is associated with chronic respiratory diseases (e.g., chronic obstructive pulmonary disease [COPD]) as well as symptoms such as cough, wheezing and sputum production [1-3].

Numerous validated self-report measures for assessing respiratory symptoms have been published. However, these instruments were primarily developed and validated specifically for use in patient populations with COPD, a severe inflammatory lung disease that causes airflow blockage and breathing- 
related problems. However, symptoms appear prior to formal disease diagnosis [1-3], making these measures less appropriate for smokers who may not (yet) have been diagnosed with a respiratory condition, but may exhibit some respiratory symptoms [4].

Questionnaires developed for diagnosed patients may not be appropriate for smokers without pulmonary disease. Many of these questionnaires include items that represent severe disease states that may or may not be applicable to smokers without clinical respiratory disease, e.g., "I am not at all confident leaving my home because of my lung condition" (COPD Assessment Test [CAT][5]), "I feel that I am not in control of my chest problems" (St. George's Respiratory Symptom Questionnaire [SGRQ][6]), "In the past 2 weeks, my cough has interrupted conversation or telephone calls" (Leicester Cough Questionnaire [LCQ] [7]), "on average, during the past week, how often did you feel: depressed (down) because of your breathing problems?" (Clinical COPD Questionnaire [CCQ])[8]. When a respiratory symptom questionnaire's items are too "difficult" (i.e., reflect symptoms of severe pulmonary disease) for the population being assessed, this leads to reduced measurement precision due to a poor match between items and persons and can also result in a "floor effect," which inhibits measurement of true reduction in respiratory symptoms over time. Furthermore, scoring and interpretation of existing measures that were developed and validated specifically for diseased populations cannot be assumed to extend to nondiseased populations. Thus, there is a need to develop and validate a respiratory symptom questionnaire that is appropriate for use with adult current and former smokers without pulmonary disease who may be experiencing mild to moderate pulmonary symptoms.

Electronic cigarettes (e-cigarettes) or electronic nicotine delivery systems (ENDS) do not burn tobacco, potentially reducing users' exposure to toxicants and carcinogens compared to combustible cigarettes [9]. The literature is mixed regarding the respiratory effects of ENDS: some reviews have concluded that switching from cigarette smoking to ENDS is associated with reduced levels of self-reported respiratory symptoms $[10,11]$, whereas others have concluded that the existing evidence is not sufficient to determine whether the adverse respiratory effects of ENDS are less than those of combustible cigarettes [12]. Contributing to the difficulty in addressing this research question is the lack of an appropriate selfreport measure of respiratory symptoms. Importantly, a valid self-report measure of respiratory symptoms appropriate for smokers - including those without diagnosed respiratory disease - is needed in order to determine whether switching completely from combustible cigarettes to ENDS leads to a reduction in respiratory symptoms.

Therefore, the primary objective of this multi-phase research was to develop and validate a respiratory symptom questionnaire that is appropriate for a general population of adult current and former smokers, including those without COPD. Questionnaire development involved three phases: (1) drafting a preliminary instrument; (2) refining the draft instrument through multiple waves of semi-structured cognitive debriefing interviews; and (3) quantitatively evaluating the psychometric functioning of the instrument. Instrument development and validation included anticipated end-users of the questionnaire, that is, adult current cigarette smokers ("Smokers") and adult former smokers who switched completely from cigarettes to ENDS ("Switchers") without COPD to ensure that the resulting questionnaire would be 
valid for use with these populations. This research also included formers smokers who had not used any tobacco product in 6+ months ("Former Smokers") as well as participants who reported a diagnosis of COPD or another respiratory symptom-related disease (e.g., asthma) for purposes of the psychometric evaluation.

Separate from the study objective of measure development and validation, these data also provided an opportunity for additional exploratory analyses examining how respiratory symptoms reported by Switchers compared to symptoms reported by Smokers and Former Smokers.

\section{Methods}

The study protocol and consent forms were approved by the Sterling Institutional Review Board (IRB ID: 8613). Development of the initial questionnaire (Phase 1) and cognitive testing methodology and results (Phase 2) are provided in Additional File 1. A summary of the Quantitative Psychometric Evaluation methods is provided here, and details are provided in Additional File 1.

The RSQ was administered as part of an online survey to Smokers, Switchers, and Former Smokers ("Time 1 Survey"). Approximately 1 week later, participants who completed the survey were re-contacted and asked to complete the RSQ a second time ("Time 2 Survey") for purposes of evaluating test-retest reliability. The final study sample included $N=610$ participants, including $n=202$ Smokers, $n=208$ Switchers, and $n=200$ Former Smokers; 128 of these participants comprised the retest sample for evaluating test-retest reliability.

\section{Analytic Plan}

A 2-parameter IRT model appropriate for polytomous items, the graded response model (GRM)[26], was fit in Mplus. The GRM's assumption of ordinality of response categories was empirically evaluated by fitting a generalized partial credit model (GPCM)[34,35]. To evaluate the GRM's assumption of unidimensionality, a Monte Carlo simulation (parallel analysis) with 10,000 randomly generated datasets was conducted using a principal components analysis (PCA) extraction method. Test information and reliability were evaluated within the context of the GRM. Stability of the RSQ was evaluated by calculating an absolute intraclass correlation coefficient (ICC) between RSQ scores from the Time 1 and Time 2 Surveys among participants who completed the RSQ at both time points. As a proxy for ability to detect change, differences between Smokers and Former Smokers' scores were evaluated via an independent samples $t$-test. Convergent validity was evaluated by calculating a Spearman correlation between RSQ scores and self-reported global health status, and by evaluating RSQ scores by diagnostic status via independent samples $t$ tests. Similarly, using independent samples $t$-tests, exploratory analyses evaluated differences between Switchers' RSQ scores compared to Smokers' and Former Smokers' scores.

\section{Results}


The draft RSQ, generated from Phases 1 and 2 and subject to quantitative psychometric evaluation in Phase 3, is presented in Table 1. The RSQ is written below an $8^{\text {th }}$ grade reading level (Flesch-Kincaid Grade Level $=7.7$ ).

\begin{tabular}{|c|c|}
\hline $\begin{array}{l}\text { Questionnaire } \\
\text { Component }\end{array}$ & Content \\
\hline Instructions & $\begin{array}{l}\text { For the following questions, please think about your experiences in th } \\
\text { days. }\end{array}$ \\
\hline Item Stem & Over the past 30 days, how often did you experience the following? \\
\hline \multirow{5}{*}{$\begin{array}{l}\text { Response } \\
\text { options }\end{array}$} & Never ( 0 days out of the last 30 days) \\
\hline & Rarely (1-5 days) \\
\hline & Occasionally (6-15 days) \\
\hline & Most days (16-29 days) \\
\hline & Every day (all 30 days out of the last 30 days) \\
\hline $\begin{array}{l}\text { Item 1: } \\
\text { Morning } \\
\text { Cough }\end{array}$ & Morning cough with phlegm or mucus \\
\hline
\end{tabular}

\section{Item 2: Cough Cough frequently throughout the day} Frequently
Item 3: $\quad$ My shortness of breath makes it difficult to do normal daily activities such as Shortness of walking up a flight of stairs or carrying a heavy object
Breath
Item 4: Easily Becoming easily winded during normal daily activities (e.g., doing laundry, carrying Winded groceries)

Item 5: $\quad$ Wheezing or whistling in your chest at times when you are not exercising or doing Wheezing other physically strenuous daily activities (e.g., while resting)

Table 1 legend: Respiratory Symptom Questionnaire content. The same set of response options are presented with each item. See Administration and Scoring.

\section{Phase 3: Quantitative Psychometric Evaluation}

\section{Rating Scale Functioning}

Observed category averages and category thresholds derived from the GPCM were ordered as expected (Additional File 1), providing empirical evidence that it requires a higher frequency of respiratory symptoms in order to endorse a more severe response option (e.g., "Every day" vs. "Most days"). 
Results from the parallel analysis revealed one significant factor (eigenvalue $=3.14$ ), providing support for unidimensionality of the RSQ (Additional File 1). This factor accounted for $62.7 \%$ of the variance.

\section{Graded Response Model (GRM)}

After confirming unidimensionality and ordinality of response options, the GRM was fit in Mplus using the weighted least-squares estimator and theta parameterization. Fit statistics for the initial GRM indicated poor fit of the data to the model (chi-square $=285.086, d f=5, p<.001 ; \mathrm{CFI}=0.963$; RMSEA $=0.303$; SRMR $=0.085)$. Due to the conceptual similarity between items, in conjunction with large observed modification indices, the model was re-run allowing for two correlated errors ("Morning Cough" and "Cough Frequently," and "Shortness of Breath" and "Easily Winded"). This model exhibited acceptable fit (chi-square $=3.056$, $d f=3, p=0.383 ; \mathrm{CFI}=1.000 ; \mathrm{RMSEA}=0.006 ; \mathrm{SRMR}=0.005)$.

The RSQ items' discrimination parameters were approximately 1 or higher, suggesting that the items were effectively differentiating between respondents with different levels of respiratory symptoms. Item 5 ("Wheezing") had the highest discrimination value (3.18), indicating that this item contributed the most in estimating respondent's total RSQ scores. The RSQ items' discrimination parameters are presented in Table 2, along with the difficulty parameters generated from the GRM.

Table 2 RSQ parameter estimates from the graded response model (GRM)

\begin{tabular}{|llllll|}
\hline Item & $\begin{array}{l}\text { Item } \\
\text { discrimination } \\
\text { (SE) }\end{array}$ & \multicolumn{2}{l}{ Difficulty parameters } & 3 & \\
\cline { 3 - 7 } & & $\begin{array}{l}\text { (Nevervs. } \\
\text { Rarely or } \\
\text { higher) (SE) }\end{array}$ & $\begin{array}{l}\text { (Rarely vs. } \\
\text { Occasionally or } \\
\text { higher) (SE) }\end{array}$ & $\begin{array}{l}\text { (Occasionally vs. } \\
\text { Most days or } \\
\text { higher) (SE) }\end{array}$ & $\begin{array}{l}\text { (Most days } \\
\text { vs. Every } \\
\text { day) (SE) }\end{array}$ \\
\hline 1 & $0.714(0.067)$ & $-0.334(0.093)$ & $1.010(0.116)$ & $2.083(0.187)$ & $3.385(0.308)$ \\
\hline 2 & $0.971(0.078)$ & $-0.183(0.075)$ & $1.032(0.094)$ & $1.953(0.146)$ & $2.866(0.225)$ \\
\hline 3 & $1.121(0.102)$ & $0.127(0.068)$ & $0.921(0.085)$ & $1.599(0.120)$ & $2.410(0.181)$ \\
\hline 4 & $1.110(0.099)$ & $-0.055(0.069)$ & $0.857(0.084)$ & $1.595(0.118)$ & $2.421(0.176)$ \\
\hline 5 & $3.179(0.885)$ & $0.337(0.053)$ & $1.113(0.072)$ & $1.767(0.107)$ & $2.282(0.151)$ \\
\hline
\end{tabular}

Table 2 legend: This table shows the parameter estimates (item discrimination values and difficulties) generated from the GRM. SE = standard error of the estimates. See Table 1 for item content.

\section{Test Information and Reliability}

The TIF produced from the GRM (Figure 1) indicates that the RSQ most precisely estimates respiratory symptoms from thetas of 0.2 to 2.4. Converting the TIF to a reliability function (Figure 2), we observe that the RSQ exhibits a reliability of 0.80 or higher from thetas of -0.40 to 3.00 . 
Next, within the context of a classical test theory framework (1) test-retest reliability of the RSQ scores, (2) differences in RSQ scores between study groups as a proxy for the RSQ's ability to detect change, and (3) convergent validity were evaluated. Given the high correlation between the GRM-derived scoring and the raw scores $(r=.94)$ and the complexities associated with using scoring from a 2-parameter IRT model, it is recommended that researchers use the raw RSQ item scores to calculate a composite (mean). Therefore, raw scores were used for the remaining analyses.

\section{Test-Retest Reliability (Stability)}

Test-retest reliability among participants who did not report being sick with a cold or flu-like symptoms at either timepoint ( $n=128$ of the 145 participants in the retest sample) was good (absolute ICC $=.89$ ).

\section{Differences Between Study Groups as a Proxy for Ability to Detect Change}

As a proxy for detecting change over time, it was anticipated that Smokers' RSQ scores would be significantly higher than Former Smokers' scores. Mean RSQ scores for Smokers and Former Smokers were $2.09(S D=.91)$ and $1.75(S D=.85)$, respectively. Smokers' RSQ scores were significantly higher than Former Smokers' scores $(t(400)=3.87, p<.001 ; d=0.39)$. Given the observed differences in years smoked between study groups, these analyses were replicated in a linear regression model controlling for years smoked. The adjusted (least squares) means were similar to the unadjusted means (Smoker $M=2.00$, Former Smoker $M=1.79)$, and the groups' RSQ scores remained significantly different $(p=.018)$. Nonparametric testing with a Mann-Whitney $U$ test, conducted as a sensitivity check, yielded the same conclusions (i.e., $p<.001$ ).

Exploratory analysis: Additional differences between study groups. As an exploratory analysis, independent samples $t$-tests were conducted to evaluate whether there were significant differences between Switchers and (1) Smokers' and (2) Former Smokers' RSQ scores. Switchers' mean RSQ scores were 1.72 (SD=.69). Switchers' RSQ scores were significantly lower than Smokers' $(t(374.84)=4.59, p$ $<.001 ; d=0.46)$, and did not differ from Former Smokers' scores $(t(382.44)=0.34, p=.736 ; d=0.03)$. These conclusions remained when regression models were used to control for the number of years smoked: adjusted (least squares) means were similar to the unadjusted means (Switcher $M=1.76$ ), and the RSQ scores of Smokers and Switchers $(p=0.005)$ remained significantly different, while the scores of Switchers and Former Smokers did not differ $(p=0.679)$.

\section{Convergent Validity}

As anticipated, higher RSQ scores were related to poorer self-reported health status $\left(r_{s}=.38, p\right.$ $<.001)$. With respect to known-groups validity, RSQ scores were significantly higher among participants who reported one or more respiratory symptom-relevant diagnoses $(M=2.16, S D=.92)$ compared to those who did not $(M=1.58, S D=.64 ; t(496.07)=8.86, p<.001, d=.74)$; similarly, RSQ scores were significantly higher among participants who reported a diagnosis of $\operatorname{COPD}(M=2.76, S D=.92)$ when compared to 
participants who did not $(M=1.67, S D=.68 ; t(126.94)=11.55, p<.001, d=1.52)$. Nonparametric testing (Mann-Whitney U test) yielded the same conclusions (i.e., $p$ 's <.001).

\section{Exploratory Analysis: Association Between RSQ and COPD}

Results from the linear regression with self-reported COPD and non-COPD diagnoses as the predictors (i.e., asthma, allergies, congestive heart failure, obesity) revealed that these diagnoses accounted for $29.2 \%$ of the variance in RSQ scores. After controlling for all other respiratory symptom-related diagnoses, COPD diagnosis was significantly related to RSQ scores $(p<.001)$ and explained $20.6 \%$ of the variance. Controlling for age and years smoked did not have a material impact on results with a small increase in the overall variance accounted for by the model (31.1\%) and COPD diagnosis was still significantly related to RSQ scores $(p<.001)$ and explained $17.0 \%$ of the variance.

Finally, to directly evaluate the relationship of RSQ scores to self-reported COPD diagnosis, a logistic regression was run with COPD diagnosis as the outcome and RSQ scores as univariate predictors. The analysis showed that with every 1-unit increase in mean RSQ scores, the odds of COPD were 4.72 times greater $(95 \% \mathrm{Cl}=3.47-6.40, p<.001)$.

\section{Administration and Scoring}

See Additional File 1.

\section{Discussion}

Accurately evaluating respiratory symptoms is likely to be useful in many contexts, and is particularly important for assessing the health consequences of tobacco product use and informing smoking cessation, as a reduction in respiratory symptoms has been shown to be associated with increased motivation to quit smoking [39-42]. Ameliorating respiratory symptoms may be a particularly motivating driver for smokers to stop smoking as respiratory symptoms may be experienced as tangible and relatable and reflect more immediate consequences of smoking. However, research evaluating respiratory symptoms among current and former smokers without diagnosed clinical pulmonary disease has been hindered due to measurement challenges, i.e., lack of a self-report questionnaire valid for assessing respiratory symptoms among non-diseased populations. Consequently, the RSQ fills an important gap in the existing toolkit of respiratory symptom patient reported outcome measures as appropriate for use with adult current and former smokers (Switchers) without a formal diagnosis of COPD.

RSQ development and validation was a rigorous multi-phase process conducted in accordance with best practices. The questionnaire was quantitatively evaluated through a psychometric evaluation leveraging both modern and classical test theory approaches. One benefit of leveraging IRT was that it allowed for evaluation of the RSQ's ability to precisely estimate respiratory symptoms among smokers with varying levels of symptomatology (i.e., estimate the amount of information that the RSQ provides at different thetas). The RSQ was found to have the highest measurement precision (information) and reliability 
when estimating respiratory symptoms for smokers with average to above average (0 to 3 SD above the mean) respiratory symptoms; importantly, these likely represent the range of thetas that are of interest when assessing respiratory symptoms among smokers with and without COPD. While the RSQ may less precisely estimate respiratory symptoms for smokers with very minimal respiratory symptomology, high measurement precision in this subpopulation is unlikely of particular importance.

Aside from the 1-week test-retest interval, the current study was not longitudinal in nature and did not permit evaluation of intra-individual change in respiratory symptoms as smokers abstained from smoking or switched completely from combustible cigarettes to ENDS over time. However, as research has established a decline in respiratory symptoms following abstention from smoking [38], observed differences between Smokers' and Former Smokers' RSQ scores provide initial support for the RSQ's ability to detect change[1]. Furthermore, exploratory analyses revealed that former smokers who switched to ENDS reported significantly lower respiratory symptoms than current smokers. Moreover, Switchers' level of self-reported respiratory symptoms was similar to symptoms of former smokers no longer using any tobacco products (Former Smokers). These results provide support for the potential of switching to ENDS to mitigate smokers' respiratory symptoms.

Exploratory regression analyses revealed that COPD diagnosis was significantly related to RSQ scores above and beyond the other respiratory symptom-related diagnoses (asthma, allergies, congestive heart failure, obesity), suggesting that the symptoms assessed have some specificity for COPD. Further, each 1unit increase in RSQ scores was associated with a nearly 5 times greater odds of COPD. While the RSQ is not intended to function as a screener or diagnostic tool for COPD, results from these analyses suggest that respiratory symptoms captured by the RSQ may be related to eventual pulmonary disease.

Importantly, the RSQ was developed in a way that supports "bring your own device" (BYOD) application. For example, a single item was administered on each screen to prevent the need for scrolling and the item stem was administered on each screen along with the item to remind participants of the timeframe of reference. Allowing for electronic administration on various devices may be a useful feature of the RSQ as self-report questionnaires may be increasingly administered across various electronic platforms.

Despite using soft target quotas to recruit a demographically diverse sample of adults for Phase 2, in the first two waves of cognitive testing there were very few participants who identified as Hispanic/Latino, reported low educational attainment, and/or who met criteria for low health literacy. This was rectified by conducting a third wave of interviews exclusively with participants representing these groups to verify that the questionnaire was understood and not differentially interpreted. In Phase 3, the sample was older than anticipated, and differences were observed between study groups with respect to age and years smoked. Although this finding is not particularly surprising (e.g., that on average, Switchers appeared somewhat younger than Smokers and Former Smokers), differences between groups on certain demographic or tobacco use variables can make it more difficult to draw conclusions, even when statistically controlling for these variables. Another limitation of the current study is that it relied exclusively on self-report; tobacco use was not biochemically verified, and diagnostic status was not 
verified through medical chart review. Finally, as this study was not longitudinal in nature it was not possible to draw causal inferences between tobacco product use behavior and change in respiratory symptoms over time. Future longitudinal research should evaluate intra-individual change in smokers' respiratory symptoms following complete switching to ENDS using the RSQ and in comparison to smokers who continue smoking.

[1] Of note, this between-group analysis could also provide support for known-groups validity of the RSQ.

\section{Conclusions}

The RSQ appears to be a valid and reliable self-report questionnaire for assessing respiratory symptoms related to pulmonary disease in populations that include smokers and former smokers who have not been diagnosed with COPD. The RSQ is understood and correctly interpreted by diverse samples of respondents with respect to age, ethnicity, and health literacy status. Results from a rigorous psychometric evaluation provide evidence of unidimensionality, high levels of measurement precision across a range of relevant thetas, convergent validity, and stability over a 1-week interval. Comparisons between groups of respondents differing in smoking history provide initial support for the RSQ's ability to detect change in respiratory symptoms over time following change in smoking status. Researchers should feel confident using the RSQ to evaluate respiratory symptomology among adult current and former smokers, including those without diagnosed pulmonary disease.

\section{Abbreviations}




\begin{tabular}{|c|c|}
\hline ATSQ & American Thoracic Society Questionnaire \\
\hline BYOD & Bring Your Own Device \\
\hline CAT & Chronic Obstructive Pulmonary Disease Assessment Test \\
\hline CCQ & Clinical COPD Questionnaire \\
\hline CFI & Comparative fit index \\
\hline COPD & Chronic obstructive pulmonary disease \\
\hline e-cigarette & Electronic cigarette \\
\hline ECRHS & European Community Research Health Survey \\
\hline ENDS & Electronic nicotine delivery systems \\
\hline FDA & Food and Drug Administration \\
\hline GPCM & Generalized partial credit model \\
\hline GRM & Graded response model \\
\hline ICC & Intraclass correlation coefficient \\
\hline IRB & Institutional review board \\
\hline LCQ & Leicester Cough Questionnaire \\
\hline OLIN-Q & Obstructive Lung Disease in Northern Sweden Questionnaire \\
\hline PATH & Population Assessment of Tobacco and Health \\
\hline PCA & Principal components analysis \\
\hline RMSEA & Root mean square error of approximation \\
\hline RSQ & Respiratory Symptom Questionnaire \\
\hline SAS & Statistical Analysis Software 9.4 (SAS Institute Inc) \\
\hline SD & Standard Deviation \\
\hline SE & Standard Error \\
\hline SF-36 & 36-Item Short Form Survey \\
\hline SGRQ & St. George's Respiratory Questionnaire \\
\hline SILS & Single Item Literacy Screener \\
\hline SME & Subject matter expert \\
\hline SPSS & Statistical Analysis Software version 28 (IBM Corp) \\
\hline SRMR & Standardized root mean square residual \\
\hline
\end{tabular}

Page 11/17 


\begin{tabular}{|ll|} 
TIF & Test information function \\
\hline US & United States \\
\hline
\end{tabular}

\section{Declarations}

Ethics approval and consent to participate: This study was reviewed and approved by Sterling IRB (IRB ID 8613). All participants received complete information about the study before providing informed consent.

Consent for publication: NA

Availability of data and materials: Due to its proprietary nature, the analyzed data is not publicly available.

Competing interests: Authors S.A.M., N.G., and R.A.B are employees of Juul Labs, Inc. Authors S.S. and M.J.H. are employees of PinneyAssociates, which was contracted and paid by Juul Labs, Inc.

Funding: This work was funded by Juul Labs, Inc.

Authors' contributions: S.A.M was the Principal Investigator of this study. R.A.B. and S.S. provided consultation on study design and the analysis plan, and N.G. provided consultation during Phase 2. M.J.H. and S.A.M. analyzed the Phase 3 data. S.A.M. wrote this manuscript with input from all authors, and all authors reviewed and approved the final manuscript.

Acknowledgements: Juul Labs, Inc. contracted with a vendor, Kantar LLC., to conduct this research. Specifically, Kantar LLC was responsible for participant recruitment for Phases 2 and 3, conducting the Phase 2 cognitive interviews, and data collection for Phase 3. Pinney Associates was also contracted by Juul Labs, Inc. to assist with data analysis for Phase 3.

\section{References}

1. U.S. Department of Health and Human Services. Smoking Cessation: A Report of the Surgeon General. Rockville, MD: Public Health Service Office of the Surgeon General; 2020.

2. U.S. Department of Health and Human Services. Publications and Reports of the Surgeon General. How Tobacco Smoke Causes Disease: The Biology and Behavioral Basis for Smoking-Attributable Disease: A Report of the Surgeon General. Atlanta (GA): Centers for Disease Control and Prevention (US); 2010.

3. U.S. Department of Health and Human Services. Reports of the Surgeon General. The Health Consequences of Smoking-50 Years of Progress: A Report of the Surgeon General. Atlanta (GA): Centers for Disease Control and Prevention (US); 2014. 
4. Soriano JB, Polverino F, Cosio BG. What is early COPD and why is it important? Eur Respir J. 2018;52(6).

5. Jones PW, Harding G, Berry P, Wiklund I, Chen WH, Kline Leidy N. Development and first validation of the COPD Assessment Test. Eur Respir J. 2009;34(3):648-54.

6. Jones PW, Quirk FH, Baveystock CM. The St George's Respiratory Questionnaire. Respir Med. 1991;85 Suppl B:25-31; discussion 3-7.

7. Birring SS, Prudon B, Carr AJ, Singh SJ, Morgan MD, Pavord ID. Development of a symptom specific health status measure for patients with chronic cough: Leicester Cough Questionnaire (LCQ). Thorax. 2003;58(4):339-43.

8. van der Molen T, Willemse BW, Schokker S, ten Hacken NH, Postma DS, Juniper EF. Development, validity and responsiveness of the Clinical COPD Questionnaire. Health Qual Life Outcomes. 2003;1:13.

9. National Academies of Sciences E, Medicine, Health, Medicine D, Board on Population H, Public Health P, et al. In: Eaton DL, Kwan LY, Stratton K, editors. Public Health Consequences of E-Cigarettes. Washington (DC): National Academies Press (US). Copyright 2018 by the National Academy of Sciences. All rights reserved.; 2018.

10. Polosa R, O'Leary R, Tashkin D, Emma R, Caruso M. The effect of e-cigarette aerosol emissions on respiratory health: a narrative review. Expert Rev Respir Med. 2019;13(9):899-915.

11. Goniewicz ML, Miller CR, Sutanto E, Li D. How effective are electronic cigarettes for reducing respiratory and cardiovascular risk in smokers? A systematic review. Harm Reduct J. 2020;17(1):91.

12. Gotts JE, Jordt SE, McConnell R, Tarran R. What are the respiratory effects of e-cigarettes? Bmj. 2019;366:I5275.

13. Cibella F, Campagna D, Caponnetto P, Amaradio MD, Caruso M, Russo C, et al. Lung function and respiratory symptoms in a randomized smoking cessation trial of electronic cigarettes. Clin Sci (Lond). 2016;130(21):1929-37.

14. Cassidy RN, Tidey JW, Colby SM. Exclusive E-Cigarette Users Report Lower Levels of Respiratory Symptoms Relative to Dual E-Cigarette and Cigarette Users. Nicotine Tob Res. 2020;22(Suppl 1):S54S60.

15. Ekerljung L, Rönmark E, Lötvall J, Wennergren G, Torén K, Lundbäck B. Questionnaire layout and wording influence prevalence and risk estimates of respiratory symptoms in a population cohort. Clin Respir J. 2013;7(1):53-63.

16. Burney PG, Luczynska C, Chinn S, Jarvis D. The European Community Respiratory Health Survey. Eur Respir J. 1994;7(5):954-60.

17. Patrick DL, Burke LB, Gwaltney CJ, Leidy NK, Martin ML, Molsen E, et al. Content validity-establishing and reporting the evidence in newly developed patient-reported outcomes (PRO) instruments for medical product evaluation: ISPOR PRO good research practices task force report: part 1-eliciting concepts for a new PRO instrument. Value Health. 2011;14(8):967-77. 
18. Reeve BB, Wyrwich KW, Wu AW, Velikova G, Terwee CB, Snyder CF, et al. ISOQOL recommends minimum standards for patient-reported outcome measures used in patient-centered outcomes and comparative effectiveness research. Qual Life Res. 2013;22(8):1889-905.

19. U.S. Department of Health and Human Services Food and Drug Administration. Patient-reported outcomes measures: Use in medical product development to support labeling claims. 2009.

20. U.S. Department of Health and Human Services Food and Drug Administration. Tobacco products: Principles for designing and conducting tobacco product perception and intention studies. In: Products CfT, editor. 2020.

21. Morris NS, MacLean CD, Chew LD, Littenberg B. The Single Item Literacy Screener: Evaluation of a brief instrument to identify limited reading ability. BMC Family Practice. 2006;7(1):21.

22. Ware JE, Jr., Sherbourne CD. The MOS 36-item short-form health survey (SF-36). I. Conceptual framework and item selection. Med Care. 1992;30(6):473-83.

23. Centers for Disease Control and Prevention (CDC). Behavioral Risk Factor Surveillance System Survey Questionnaire. Atlanta, Georgia: U.S. Department of Health and Human Services, Centers for Disease Control and Prevention; 2020. p. 109.

24. Green SB. How Many Subjects Does It Take To Do A Regression Analysis. Multivariate Behav Res. 1991;26(3):499-510.

25. Schmidt FL. The Relative Efficiency of Regression and Simple Unit Predictor Weights in Applied Differential Psychology. Educational and Psychological Measurement. 1971;31(3):699-714.

26. Samejima F. Estimation of latent ability using a response pattern of graded scores. Psychometrika Monograph Supplement. 1969;34(4, Pt. 2):100-.

27. Coleman B, Rostron B, Johnson SE, Persoskie A, Pearson J, Stanton C, et al. Transitions in electronic cigarette use among adults in the Population Assessment of Tobacco and Health (PATH) Study, Waves 1 and 2 (2013-2015). Tob Control. 2019;28(1):50-9.

28. Villarroel MA, Cha AE, Vahratian A. Electronic cigarette use among U.S. adults, 2018. NCHS Data Brief, no 365. Hyattsville, MD: National Center for Health Statistics; 2020.

29. SAS Institute Inc. SAS/ACCESS ${ }^{\circledR} 9.49 .4$ ed. Cary, NC: SAS Institute Inc; 2013. p. Interface to ADABAS.

30. Muthén LK, Muthén BO. Mplus 8.6 ed. Los Angeles, CA: Muthén \& Muthén.; 2017.

31. IBM Corp. IBM SPSS Statistics for Windows. IBM Corp; 2017.

32. Brown TA. Confirmatory factor analysis for applied research. 2 ed. New York, NY, US: The Guilford Press; 2015. xvii, 462-xvii, p.

33. Hu L-t, Bentler PM. Cutoff criteria for fit indexes in covariance structure analysis: Conventional criteria versus new alternatives. Structural Equation Modeling. 1999;6(1):1-55.

34. Muraki E. A GENERALIZED PARTIAL CREDIT MODEL: APPLICATION OF AN EM ALGORITHM. ETS Research Report Series. 1992;1992(1):i-30. 
35. Muraki E. INFORMATION FUNCTIONS OF THE GENERALIZED PARTIAL CREDIT MODEL. ETS Research Report Series. 1993;1993(1):i-12.

36. Furr MR. Psychometrics- An Introduction. 4 ed. Wake Forest University, USA: SAGE Publications, Inc; 2021. $704 \mathrm{p}$.

37. Hoffman L, Templin J, Rice ML. Linking outcomes from peabody picture vocabulary test forms using item response models. J Speech Lang Hear Res. 2012;55(3):754-63.

38. U.S. Department Of Health And Human Services. Smoking Cessation: A Report of the Surgeon General. Smoking Cessation: A Report of the Surgeon General. Atlanta (GA): National Library of Medicine Cataloging-in-Publication Data; 2020.

39. Melzer AC, Feemster LC, Crothers K, Carson SS, Gillespie SE, Henderson AG, et al. Respiratory and Bronchitic Symptoms Predict Intention to Quit Smoking among Current Smokers with, and at Risk for, Chronic Obstructive Pulmonary Disease. Ann Am Thorac Soc. 2016;13(9):1490-6.

40. Hymowitz N, Cummings KM, Hyland A, Lynn WR, Pechacek TF, Hartwell TD. Predictors of smoking cessation in a cohort of adult smokers followed for five years. Tob Control. 1997;6 Suppl 2(Suppl 2):S57-62.

41. Duncan CL, Cummings SR, Hudes ES, Zahnd E, Coates TJ. Quitting smoking: reasons for quitting and predictors of cessation among medical patients. J Gen Intern Med. 1992;7(4):398-404.

42. Wellman RJ, O'Loughlin EK, Dugas EN, Montreuil A, Dutczak H, O'Loughlin J. Reasons for quitting smoking in young adult cigarette smokers. Addict Behav. 2018;77:28-33.

\section{Figures}




\section{Test Information Function}

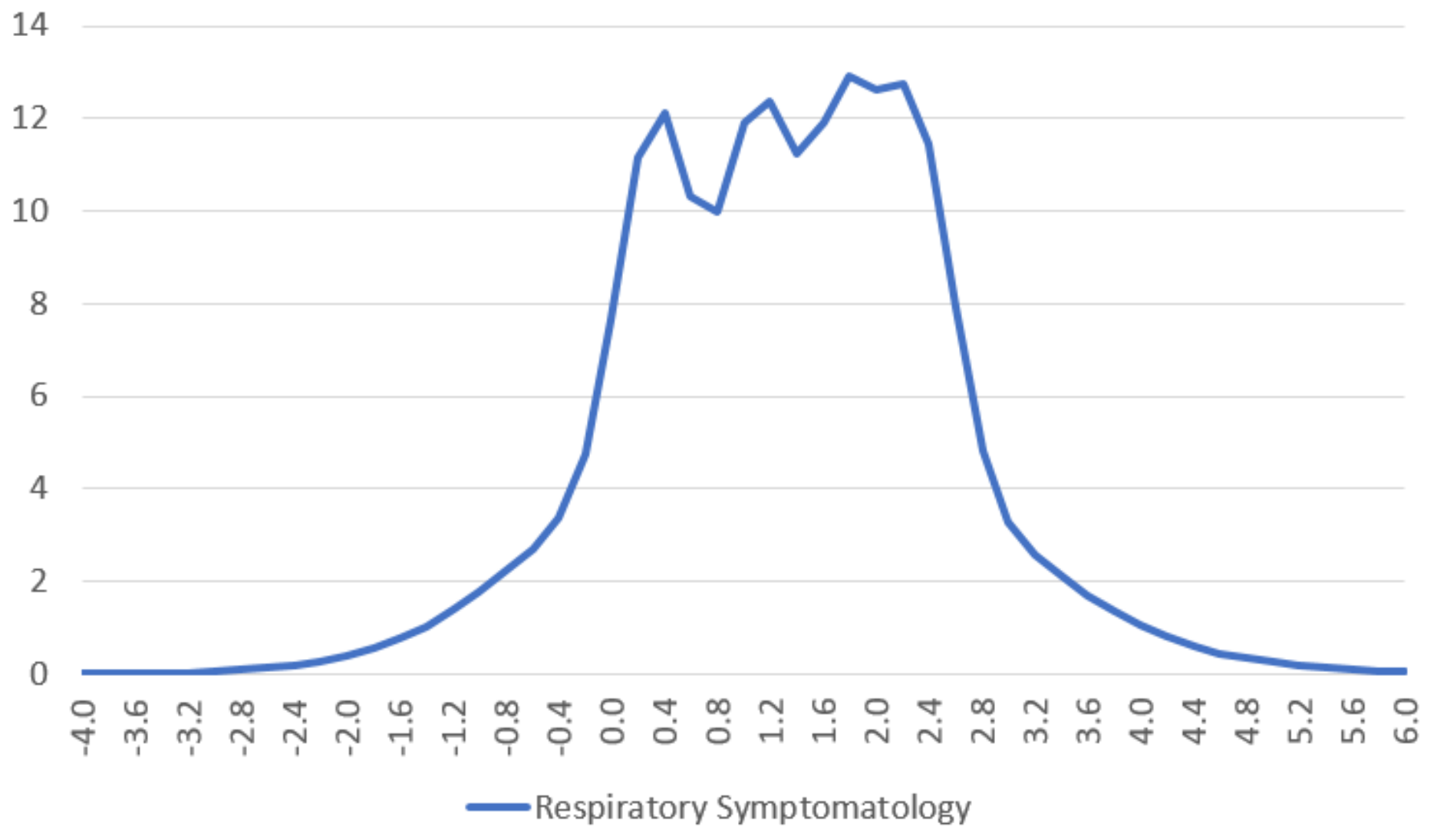

\section{Figure 1}

Test information function (TIF) of the RSQ generated from the GRM

This figure depicts the amount of information (precision) that the RSQ provides across different levels of respiratory symptoms (thetas, with mean $=0$ and standard deviation $=1$ ). 


\section{Reliability}

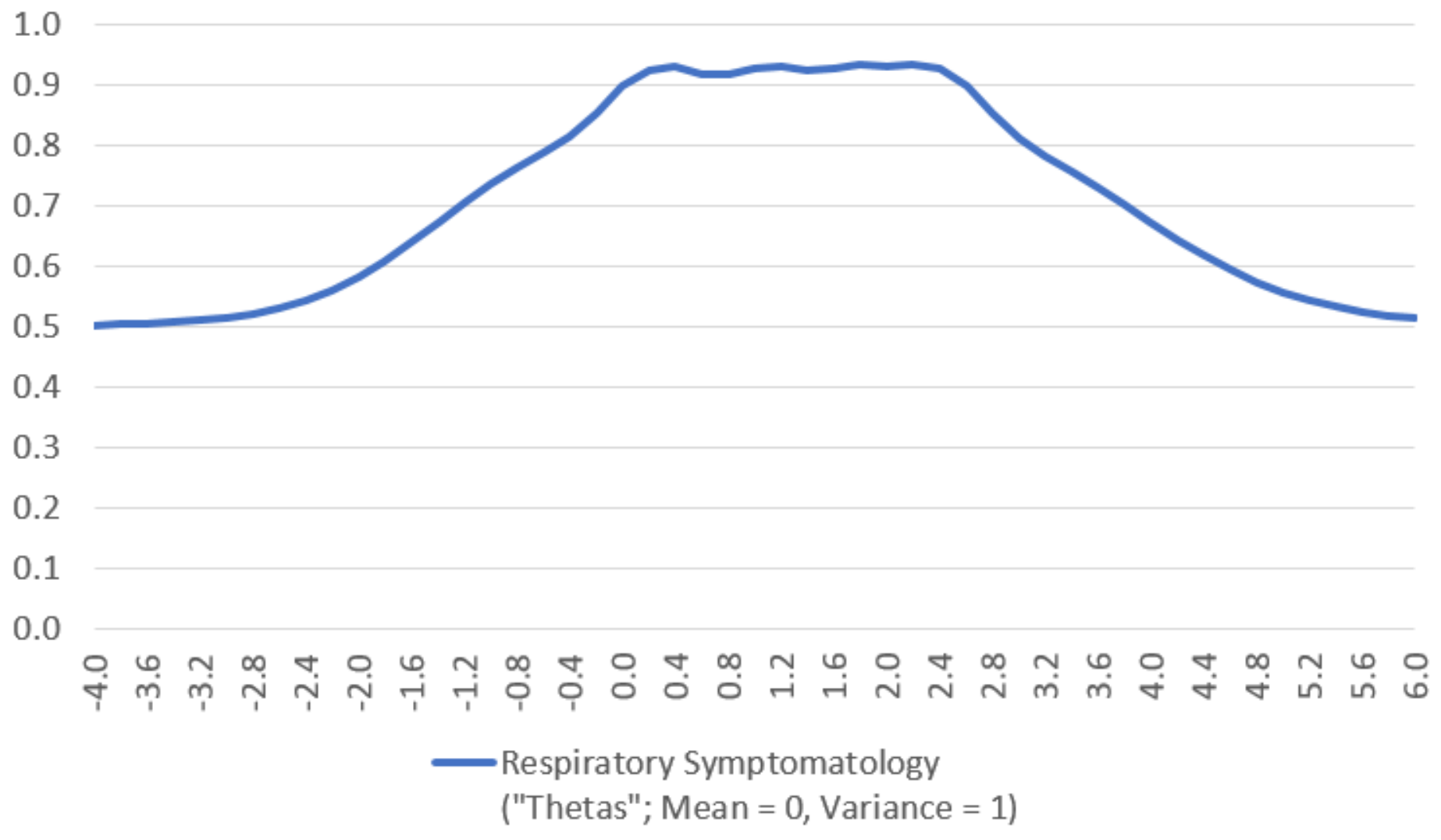

Figure 2

Reliability of the RSQ at different levels of respiratory symptoms

This figure illustrates how reliability within the context of the GRM varies across different levels of the latent trait. The RSQ exhibits the highest reliability (reliability of 0.80 or higher) from thetas of -.40 to 3.00 .

\section{Supplementary Files}

This is a list of supplementary files associated with this preprint. Click to download.

- AdditionalFile1.docx 